\title{
Deep insights into urinary tract infections and effective natural remedies
}

\author{
Bibi Sedigheh Fazly Bazzaz ${ }^{1,2}$, Sareh Darvishi Fork ${ }^{3}$, Reza Ahmadi ${ }^{4}$ and Bahman Khameneh ${ }^{2 *}$ (D
}

\begin{abstract}
Background: Urinary tract infection (UTI) is a common occurrence in females, during pregnancy, and in peri- and postmenopausal women. UTIs are associated with significant morbidity and mortality, and they affect the quality of life of the affected patients. Antibiotic therapy is an effective approach and reduces the duration of symptoms. Development of resistance, adverse effects of antibiotics, and other associated problems lead to establishing the research framework to find out the alternative approaches in controlling UTIs. Natural approaches have been extensively used for the management of various diseases to improve symptoms and also improve general health.

Main body: Different databases were employed to identify studies reporting on natural options including herbal medicines, vitamins, trace elementals, sugars, and probiotics without time limitations.

Conclusion: Herbal medicines can be effective at the first sign of the infection and also for short-term prophylaxis. Using vitamins, trace elementals, and/or sugars is an effective approach in preventing UTIs, and a combination of them with other antibacterial agents shows positive results. Probiotics have great potential for the threat of antibiotic over-usage and the prevalence of antibiotic-resistant microorganisms. This study may be of use in developing the efficient formulation of treatment of UTI.
\end{abstract}

Keywords: Urinary tract infection, Herbal medicine, Vitamin, Probiotics, Supplements, Antibacterial resistance

\section{Background}

Urinary tract infection (UTI) is one of the most prevalent bacterial infections in women and elderly individuals. This type of infection although can cause less severe lifethreatening infections but the patient experienced significant distress [1]. Additionally, this infection is associated with substantial healthcare and societal costs which is only in the USA; UTIs are responsible for 7 million clinic visits annually [2]. Except among infants and the elderly, the infection occurs more commonly in women than in men and it was estimated that about $40-50 \%$ of women experience one episode in their lives and $20-30 \%$ of them have other episodes [3]. For women between 1 year and up to 50 years, UTI and recurrent UTI (rUTI) are

\footnotetext{
*Correspondence: Khamenehbagherib@mums.ac.ir

2 Department of Pharmaceutical Control, School of Pharmacy, Mashhad

University of Medical Sciences, Mashhad, Iran

Full list of author information is available at the end of the article
}

predominantly diseases [3]. rUTI is mainly associated with abnormalities of the urinary tract detected after kidney transplantation or also secondary to end-stage renal disease. Moreover, a significant proportion of patients who develop rUTI have no identifiable causes [4].

UTI is mostly caused by bacteria, through other microorganisms such as fungi and viruses that are rare etiologic agents [5]. This type of infection can be classified as complicated or uncomplicated. Uncomplicated UTI is the most common type of infection and mainly occurs in the absence of functional or anatomical abnormalities within the urinary tract. The complicated one occurs in the presence of an abnormal urinary tract that increases susceptibility to infection [1].

Among the uropathogen, Escherichia coli is the most common bacteria (75-90\% of isolates) in both the community and hospital infections, whereas other pathogenic bacteria such as Proteus mirabilis, Staphylococcus saprophyticus (with particularly frequent isolation from 
younger female), Enterococcus faecalis, Klebsiella pneumoniae, and Pseudomonas aeruginosa each are less important [1-3]. The uropathogenic bacteria express fimbrial adhesions that they attach to the glycolipids and glycoproteins on the epithelial surface. In this way, bacteria can overcome the flow of urine and maintain in the urinary tract. The bacteria also produce other substances such as toxins, hemolysin, and colony-necrotizing factors. These agents disrupt epithelial integrity, permit bacterial invasion, and, therefore, enhance the risk of infection [6]. Uropathogens also can internalize into host epithelial cells and divide inside there, so that it provides a reservoir for recurrent infection [1].

In most cases, these uropathogens begin to colonize the surface of the perineum and periurethral and precede the development of infection. Colonization of bacteria could be inhibited by the normal microbiota, such as Staphylococcus epidermidis, Lactobacillus spp, and Corynebacteria [7]. Additionally, bacterial colonization and initial infection were eliminated by host defense mechanisms in the bladder. The foreign bodies such as urinary catheters or stone in the urinary tract provide an inert surface for bacterial colonization [3].

Female anatomy, age, sexual activity, certain types of birth control, and menopause are the most risk factors for UTI. Other risk factors are urinary tract abnormalities, blockages in the urinary tract, suppressed immune system, catheter use, and a recent urinary procedure [8].

Several types of antibiotics have been used to treat UTIs. Antibiotic therapy is an effective approach and reduces the duration of symptoms. Empirical treatment is usually with 3 days of antibiotics which achieves a cure in $85-90 \%$ of women. This type of regimen is equivalent to longer regimens and also is more effective than a single-dose administration [1,9]. Various regimens have been used to treat UTI; for men, quick antibiotic therapy for at least seven days is recommended. In the patients treated in the first line, the administration of trimethoprim and nitrofurantoin is currently used. Second-line antibiotics such as quinolones should be considered for patients with prostatitis [10]. NHS Clinical Knowledge Summaries recommend various antibiotic therapy regimens: (1) seven days of ciprofloxacin, co-amoxiclav, or cephalexin or (2) 14 days of trimethoprim for men and non-pregnant women, and (3) 7-10 days of cefalexin for pregnant women. Severe infections require hospital care and treatment with broad-spectrum parenteral antibiotics and admission for intravenous fluids.

In the last decades, the extensive use of antibiotics has resulted in the emergence of antibiotic-resistant bacterial pathogens and leads to the spread of antibiotic resistance. Additionally, because of the chronic nature of UTIs and the potential for antibiotic resistance, a promising approach to prevention and treatment is favorable. These days various approaches have been developed to overcome the problems associated with antibiotic resistance [11-13]. Complementary and alternative medicine (CAM) has been recognized as an effective approach for the treatment of infection by antibiotic-resistant bacteria [11, 14-16]. CAM consists of a wide range of products such as natural compounds, dietary supplements as vitamins and minerals, and also probiotics [17]. This type of medicine has been attracted great attention in modern countries. For example, according to statics, $1.8 \%$ of children in the USA are treated with CAM. However, the real frequency of CAM is estimated higher than this amount. Clinically research suggests the best natural options for long-term prevention include probiotics, medical herbs, vitamins, and elements that have also been shown to prevent UTIs [18-20]. So, we could hope that using CAM in the treatment of UTI could provide desirable results, especially when combined with a routine antibiotic regimen. In the present review, the most important classes of the compound which have been used in CAM are mentioned. By using these natural remedies along with conventional antibiotic therapies, better results were obtained.

\section{Main text}

This review was based on data extracted from published papers with the search terms of urinary tract infection, herbal medicine, vitamin, probiotics, supplements, and antibacterial resistance which are available in all relevant databases, especially PubMed, Web of Science, Scopus, MEDLINE, and EMBASE, without limitation up to August 1, 2020.

\subsection{Herbal medicine}

In recent years, the use of medicinal herbs in the prevention and treatment of various diseases has been increased $[13,21]$. Complimentary therapy with medicinal herbs is a research area that may be deserving of special attention. The complementary therapy of antibiotics with medicinal herbs showed mainly synergistic effects [11]. In many studies, herbal medicines could reduce bacterial resistance to antibiotics, remarkably $[15,16]$. So, in many cases, patients may benefit from this type of therapy. It was shown that herbal medicines could play an important role in the treatment of a type of UTI [22]. Since several plant antimicrobial compounds contain various functional groups in their structure, the antimicrobial activities are attributed to multiple mechanisms [13]. The chemical compounds presented in herbal medicines evolved to protect the plant from pathogenic microorganisms and therefore could prevent or treat infections in animals. Many of these compounds are renally excreted 
so that they are specifically useful as urinary antiseptic agents. Two major mechanisms are involved in the antimicrobial properties of these compounds. Some of them directly kill microbes and some of them interfere with microbial adhesion to epithelial cells [23]. These herbs play an important role in assisting to resolve UTI. Here, we briefly review the role of medicinal herbs and their variant in the treatment of infections. Some of these herbal medicines with more details are illustrated in Fig. 1.

\subsubsection{Arctostaphylos uva-ursi}

Arctostaphylos uva-ursi (bearberry) is a plant species of the genus Arctostaphylos. The leaves of this plant have been traditionally used because of their diuretic properties [23]. The plant has been used for the treatment of infectious diseases, especially for UTIs. The herb is approved in Germany for the treatment of bladder infections and effective against $E$. coli in the bladder [24].

The leaves of the plant are responsible for the therapeutic actions which contain the glycoside arbutoside. This compound is hydrolyzed in the bowel to glucose and the aglycone hydroquinone which is absorbed and glucuronidated in the liver. Hydroquinone glucuronide is then carried to the kidneys and excreted in the urine. In the alkaline condition of urine, the hydroquinone glucuronide will decompose automatically and hydroquinone
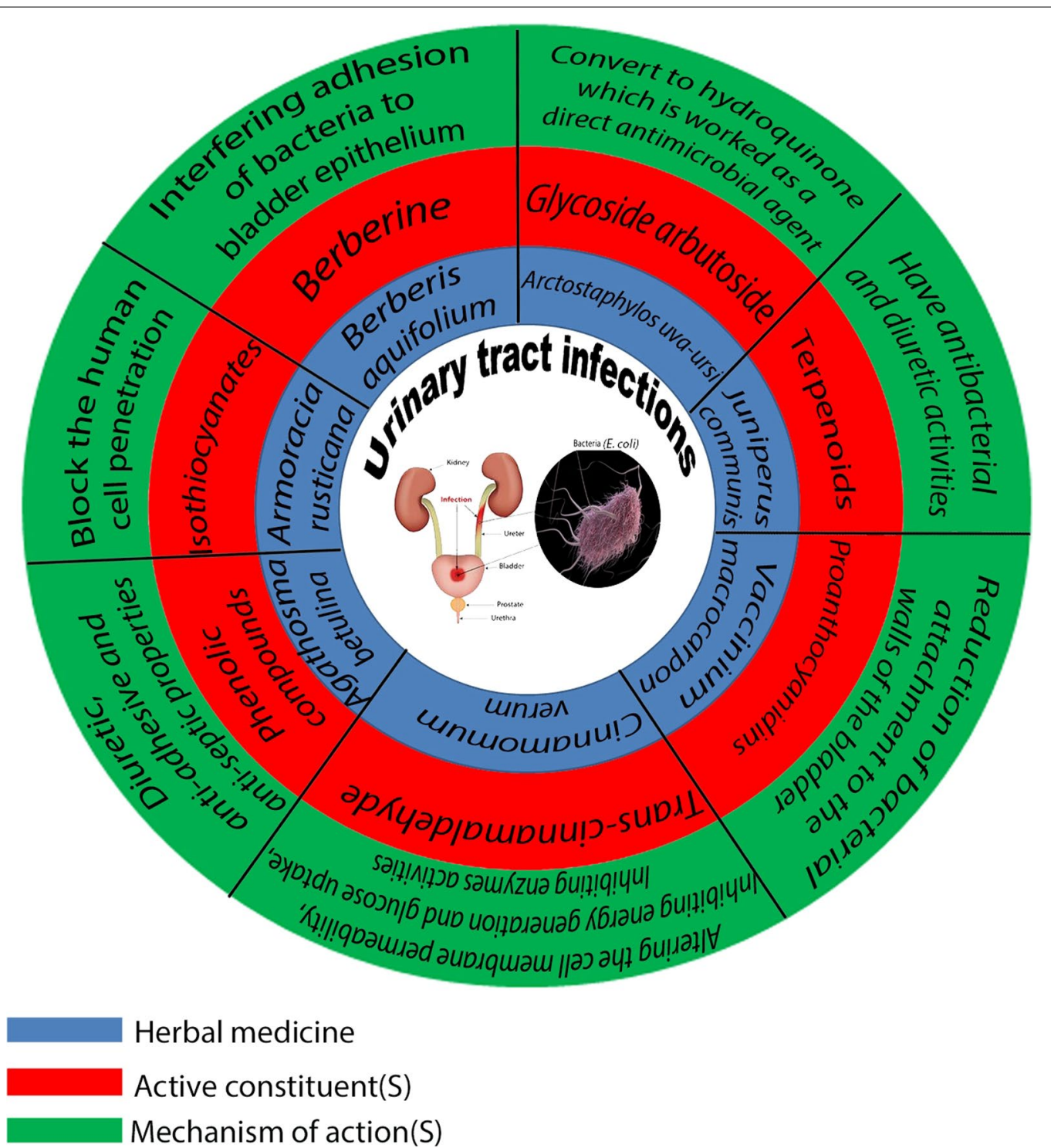

Fig. 1 Used herbal medicines in the treatment of UTI. The active constituents with the related mechanism of action(s) are also described 
which is worked as a direct antimicrobial agent will be released [23].

It should be noted that based on information from laboratory researches exposure to synthetic hydroquinone for the long-term may be carcinogenic, so that it is recommended the consecutive consumption of this herbal medicine should not be extended more than two weeks.

Tannins presented in this plant could potentiate the in vitro antibacterial activities of $\beta$-lactam antibiotics against methicillin-resistant $S$. aureus (MRSA). Consequently, due to that whole plant extracts contain other constituents that increase antibacterial activities, it is recommended to use whole plant extracts instead of isolated arbutoside.

\subsubsection{Juniperus communis}

Juniperus communis (juniper), which belongs to the Cupressaceae family, and other closely related species including Juniperus monosperma (Engelm) Sarg and Juniperus osteosperma (Utah juniper) show remarkable antimicrobial activities [25]. It was reported that terpenoids in the leaf of the herbs are responsible for the antibacterial and diuretic activities of the herbs [23]. Schilcer reported that Juniper oil was effective against urinary tract infections [26]. Leaf and berries of the plant show antimicrobial activities against urinary tract infections. The main antibacterial constituent of this plant is terpinen-4-ol, a volatile oil, which plays an important role in the treatment of UTIs [27]. This plant also contains other active agents such as oxygenated sesquiterpene, $\beta$-pinene, sabinene, monoterpene hydrocarbons, limonene, and myrcene [22]. It should be noted that the volatile oil of juniper contains nephrotoxic compounds, especially hydrocarbon terpenoids. However, these adverse effects might only be seen after receiving high doses which far exceeded the therapeutic dose [23].

It was indeed previously demonstrated that the extracts presented diuretic activity [27]. The juniper leaf infusions show more diuretic activity than the volatile oil, which suggests that other constituents contribute to the diuretic activity of the herb.

\subsubsection{Vaccinium macrocarpon (cranberry)}

Many researchers have suggested that cranberry is active against UTIs. The plant belongs to Ericaceae family and can be potentially active against $E$. coli, the leading causes of bacteria-mediated UTIs, by reduction of bacterial attaching to the walls of the bladder, and then, the bacteria are more likely to be washed out during urination. Cranberry juice intake leads to measurable protection against both sensitive and resistant strains of E. coli [28]. It could also inhibit the binding of bacteria to gastrointestinal mucosa [29]. It was shown that cranberry juice consumption reduced the biofilm formation of both Gram-negative and Gram-positive uropathogens [30, 31].

Cranberry contains proanthocyanidins, which are stable phenolic compounds and contribute to the anti-adhesion activity against $E$. coli. Also, the in vitro antibacterial activities of cranberry extracts and juice against other pathogens such as $S$. aureus, $P$. aeruginosa, K. pneumoniae, and P. mirabilis have been previously demonstrated [32]. Cranberry proanthocyanidins mainly contain A-type and B-type linkages, while in comparison with B-type linkage, A-type linkage is more effective in preventing adhesion of $\mathrm{P}$-fimbriated uropathogenic E. coli to uroepithelial cells of the bladder and responsible for anti-adhesion activities of the extract, therefore inhibiting the ability of $E$. coli to infect the urinary mucosa [33, 34].

Cranberry also contains other biologically active constituents such as anthocyanidin, catechin, flavanols, myricetin, quercetin, and phenolics which are supposed to be responsible for its activities [35].

The other possible mechanism of action of cranberry might be related to acidification of the urine; however, it only causes temporary effects, and the changes last about 15 min in most people. Therefore, this mechanism could not be of relevance.

Due to these health benefits of cranberry extract, different commercial formulations of the extract exist in the market. In acute situations, the usual dose of the juice is 250-500 $\mathrm{ml}$ two to three times daily and for prevention consumption of $250-500 \mathrm{ml}$ per day is enough. The solid dosage forms such as capsules that contain concentrated cranberry extract are also available. In acute situations, taking 2-3 capsules two to four times per day and taking 1 two to three times daily for prevention are recommended [36].

In summary, the existing data indicate the beneficial effects of cranberry preparations against UTIs; however, these effects are mainly related to prophylactic activities by preventing the development of infections or in combination with conventional antibiotics and solely intake of the herb is not recommended for UTI treatment.

\subsubsection{Vaccinium myrtillus (Blueberry)}

Blueberry has extensively been used traditionally to treat and prevent UTI. Blueberry extracts contain similar constituents as cranberry extracts, and the extracts possess similar anti-adhesive activities against uropathogenic bacteria and the bacteria are significantly less able to adhere to the walls of the bladder [24, 37]. Tannins are the most active constituents of blueberry extracts against UTI. 


\subsubsection{Cinnamomum verum (Cinnamon)}

Cinnamon belongs to the Lauraceae family and shows antioxidant and antibacterial activities. It contains bioactive phytochemical compounds such as trans-cinnamaldehyde, eugenol, trans-cinnamyl acetate, and proanthocyanidins which have been used in the treatment of UTI.

Amalaradjou et al. showed that trans-cinnamaldehyde as an essential oil was able to inhibit biofilm formation of $E$. coli on urinary catheters by downregulating major virulence genes in the bacteria.

Various mechanisms are involved in antibacterial activities of essential oils: (I) due to their hydrophobicity, these molecules could target the lipid-containing bacterial cell membrane and mitochondria and alter the permeability which finally leads to leakage of ions and other cell contents, (II) inhibiting energy generation and glucose uptake, and (III) inhibiting activities of important enzymes such as amino acid decarboxylases [38].

\subsubsection{Agathosma betulina (buchu)}

A. betulina is one of the oldest known herbs for the treatment of uncomplicated UTI [39]. The leaves of the herb contain various phenolic compounds and have been used as an herbal remedy for urinary tracts, because of the diuretic and antiseptic properties. In a study, it was demonstrated that the ethanolic leaf extract of $A$. betulina showed antibacterial activities against E. coli, K. pneumoniae, P. mirabilis, P. aeruginosa, S. aureus, Staphylococcus saprophyticus, and E. faecalis [40]. For a preparation containing the leaves extract of $A$. betulina, the anti-adhesive properties were investigated, and the results showed the anti-adhesive effects of the preparation by interacting with T24 cells [41].

\subsubsection{Hybanthus enneaspermus}

$H$. enneaspermus was studied to evaluate the in vitro antibacterial activity of various types of extracts against the major UTI including E. coli, P. aeruginosa, K. pneumoniae, P. mirabilis, E. faecalis, and S. aureus. Among the extracts, ethanol extract showed the most antibacterial activities against the pathogens. The extract has various bioactive compounds such as flavonoids, terpenes, phenolic, and alkaloids that the therapeutic values are attributed to the presence of them.

\subsubsection{Armoracia rusticana (horseradish)}

A. rusticana (synonyms: Cochlearia armoracia, Radicula armoracia), which belongs to the family Brassicaceae, traditionally has been used to treat UTI. It shows favorable results for the prevention of recurrent UTI in pediatric patients [42]. It was demonstrated that the isothiocyanates of horseradish are responsible for their antibacterial activities of the herb. It was shown that these bioactive compounds could block the pathogenic process of human cell penetration by uropathogenic $E$. coli [43].

\subsubsection{Hydrastis canadensis (Goldenseal)}

$H$. canadensis (Goldenseal) has been used traditionally to treat various diseases such as digestive disorders, UTI, and skin diseases and also to check internal hemorrhage [44]. The rhizome, rootlets, and root hairs of the herb produce bioactive alkaloids and isoquinoline alkaloids [45]. These bioactive compounds may act similarly to proanthocyanidins, which are found in cranberry, in inhibiting bacteria from sticking to the bladder walls [24].

Berberine is a bioactive herbal alkaloid which presents in various medicinal plants such as $H$. Canadensis, Berberis aquifolium, B. vulgaris, and B. aristata [13]. This compound has been used in the treatment of UTI [46]. Notably, berberine exerts its antibacterial activities against UTI with interfering adhesion of E. coli to bladder epithelium.

\subsubsection{Equisetum arvense (Horsetail)}

E. arvense (Horsetail) is one of the oldest and most famous herbal medicine. The plant has a vast variety of therapeutic properties such as antibacterial activities $[47,48]$. It was shown that the ethanol extract of the herb showed antibacterial activities against urinary tract pathogens including E. coli, K. pneumonia, P. mirabilis, $P$. aeruginosa, $S$. aureus, $S$. saprophyticus, and E. faecalis. The commonly known phytochemical compounds from Horsetail are alkaloids, phytosterols, tannin, triterpenoids, and phenolics [49]. Among them, phenolic compounds, especially flavonoids, present in the plant extracts are responsible for the antibacterial activities [50]. The essential oil of the herb was shown to possess broad-spectrum antimicrobial activities against tested strains.

\subsubsection{Urtica dioica (nettle)}

$U$. dioica (nettle) is a perennial plant of the Urticaceae family and has been traditionally used for the treatment of various diseases such as arthritis, rheumatism, UTI, kidney stones, and gingivitis [51].

It was shown that the plant extracts exhibit antimicrobial activities against various Gram-positive and Gram-negative bacteria such as Bacillus subtilis, Lactobacillus plantarum, P. aeruginosa, E. coli, K. pneumoniae, $S$. aureus, and S. epidermidis [52]. The leaf of the herb is a valuable source of biologically active compounds that show antimicrobial activities and could be used to treat infectious diseases [53]. 
It should be noted that the role of nettle in the treatment of UTI might be due to the diuretic activities of the herb [54].

\subsubsection{Plantago major L.}

$P$. major L. belongs to the Plantagináceae family and is used traditionally for the treatment of several diseases such as infectious diseases, pain relief, and reducing fever. The major chemical compositions of the herb include mucilage, organic acids, polysaccharides, and flavonoids. The herb traditionally has been used in Iran for pulmonary infections, stomach ulcers, and infections [55].

\subsubsection{Other herbs}

The essential oil of Salvia officinalis showed inhibitory activities against clinically isolated uropathogens [56]. Barosma betulina has been used traditionally for the treatment of various diseases such as UTI, catarrhal cystitis, and urethritis. The in vitro studies showed its antimicrobial effects against uropathogens. Other herbs that have been used for the treatment of UTIs but are not yet adequately studied include Mentha piperita, Allium sativum, Terminalia chebula, Taraxacum officinalis, and Zingiber officinale [22].

\subsection{Nutrition therapy}

Using nutrients is an integral part of the management, prevention, and treatment of UTIs. In most cases, micronutrients have been used to this end and they are included vitamins and minerals in general. The role of each agent in the prevention or treatment of UTIs is illustrated in Fig. 2.

\subsubsection{Vitamins}

Vitamin C possesses antimicrobial activities and is frequently used as an important supplement to antibiotic therapy for UTI [57]. Vitamin C is considered as a nonenzymatic antioxidant that slows down the production of free radicals and oxidation, which leads to strengthening the immune system and the deficiencies of vitamin $\mathrm{C}$ could place the persons at risk for infections due to the negative impacts on immune function [58]. Various studies have been conducted to show the efficacy of vitamin $\mathrm{C}$ in the management of UTIs. Yousefichaijan et al. studied the efficacy of vitamin C supplementation on UTI in children for 14 days. The results showed that vitamin $\mathrm{C}$ supplementation was able to control the symptoms of UTI, including dysuria, fever, urinary urgency, and also dribbling urine [59]. Ochoa et al. investigated the role of a daily intake of vitamin $\mathrm{C}$ for its effect on UTIs during pregnancy. They showed that daily usage of vitamin $C$ has significant effects on the reduction of UTIs and also improving the health level of the women [60]. The formation of struvite stones is associated with UTIs by ureaseproducing bacteria. It was shown that the vitamin can modulate the struvite crystal formation in the presence of uropathogenic bacteria [61]. In another study, the combination of cranberries, a probiotic (Lactobacillus rhamnosus), and vitamin C has been used to evaluate the clinical benefits due to their additive or synergistic effects. The results showed that the approach might represent a safe and effective option in UTI management [62]. It was shown that nitrite may be generated by bacteria in urine during UTI. Acidification of nitrite leads to the formation of nitric oxide (NO) and other reactive nitrogen oxides that are toxic for a wide range of microorganisms. In a study, NO formation and bacterial growth in mildly acidified urine containing nitrite and vitamin $\mathrm{C}$ as a reducing agent were investigated. The growth of bacteria was markedly reduced by the addition of nitrite to acidified urine. Additionally, the inhibition was enhanced by vitamin C. These results help to explain the bacteriostatic effects of acidified nitrite because of the release of $\mathrm{NO}$ and other toxic reactive nitrogen intermediates and also the role of vitamin $\mathrm{C}$ in the treatment and prevention of UTI [63].

The positive role of vitamin A supplementation in the prevention and treatment of UTI has been mentioned previously [64]. Vitamin A has been used in the management of UTIs in children. The results of the study indicated that in the group of the children who received 200,000 IU of the vitamin in combination with antibiotics, the incidence of UTIs was lower than the control group [65]. In another study, vitamin A supplementation in addition to antimicrobial therapy was used to improve UTI symptoms and preventing renal scarring in girls who suffer from acute pyelonephritis. The results showed that vitamin A supplementation is an effective approach for improving the clinical symptoms of UTI and also reducing the renal injury and scarring following acute pyelonephritis [66]. Sobouti et al. studied the effects of vitamin A or E supplementation in addition to antimicrobial therapy for the prevention of renal scarring in acute pyelonephritis. According to the results, vitamins A or E supplements were effective in reducing renal scarring secondary to acute pyelonephritis [67]. The other study was conducted to determine the effect of vitamin A supplementation on the rate of permanent renal damage in children with acute pyelonephritis. It was demonstrated that the administration of vitamin A leads to a significant reduction in permanent renal damage [68].

Different mechanisms have been mentioned for the implication of vitamin D on the management of UTI. It was shown that tight junction proteins play important roles in preventing the bacterial invasion of the epithelial 

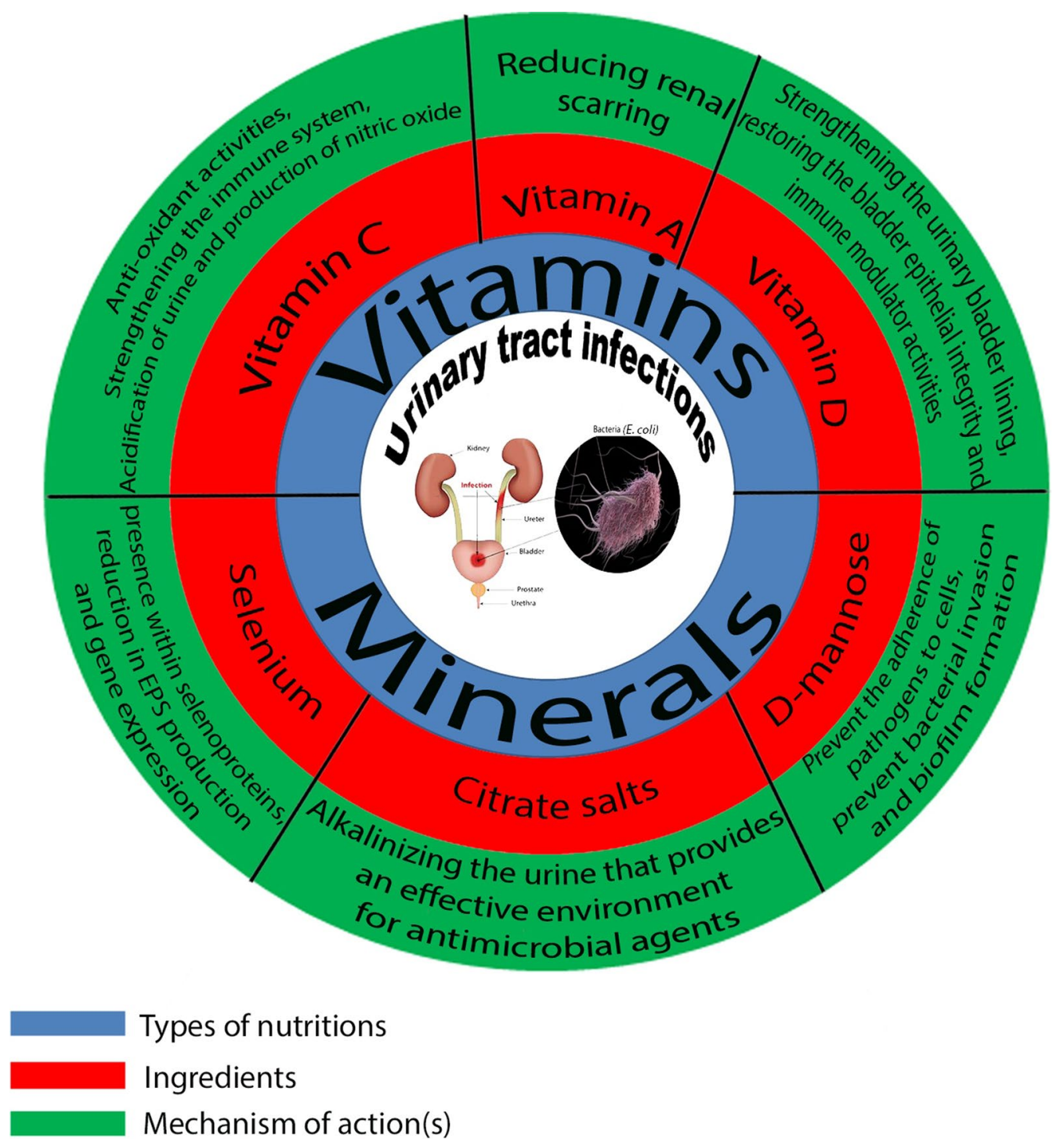

Fig. 2 The role of nutrition therapy in the prevention and treatment of UTIs. The ingredients with the related mechanism of action(s) are also described

barrier and supplementation with vitamin D could strengthen the urinary bladder lining and restore the bladder epithelial integrity [69]. Additionally, on the one hand, vitamin $\mathrm{D}$ could act as a local immune response mediator in UTI and on the other hand, enhancing vitamin D levels leads to modulate the innate immune system and provides a protective response to infection [70, 71]. The relation between the status serum level of vitamin D and the risk of UTI has been studied extensively, and the results showed a significant association between increased risk of UTI and vitamin D insufficiency, as an independent risk factor, especially in children [72-74]. Women with vitamin $\mathrm{D}$ deficiencies show a higher risk level of UTI during pregnancy [75]. Vitamin D deficiency is common and the proven risk factor for UTIs especially in girls and supplementation with vitamin D could prevent first-time UTI [76]. In a randomized clinical trial, the subjects who received vitamin D3 (20,000 IU per week) for five years showed better prevention against UTI [77]. Together, these results demonstrate that vitamin D supplementation provides a potent weapon in the prevention of UTI.

\subsubsection{Minerals}

The role of zinc in the management of the infectious disease has been described extensively $[17,78]$. It was shown 
that the element increases the response to treatment in many infections and active against different pathogens such as E. coli, Mycobacterium tuberculosis, Salmonella typhi, and Streptococcus pyogenes [79-81]. The incidence of zinc deficiency in infectious disease clinics has been reported extensively $[82,83]$. The results of the Mohsenpour et al. study showed that serum zinc levels in people with recurrent UTI were lower than those in the control group. So, the zinc level could be assumed as a risk factor for recurrent UTI [84]. In another study, the relation between serum zinc levels in children inflicted with UTI and the control group was assessed. According to the data, lower zinc levels were associated with susceptibility to UTI, and therefore, zinc administration has been suggested [85].

Microbial infections are often associated with selenium deficiencies. The main physiological properties of this micronutrient are directly attributed to its presence within selenoproteins [11]. Selenium at a certain concentration was effective in preventing uropathogenic E. coli biofilm formation on urinary catheters. Further, the inhibitory effects were associated with a reduction in EPS production and gene expression of the bacteria. Additionally, at higher concentrations, selenium was effective in inactivating preformed bacterial biofilms on catheters within 3 days of incubation. These observations suggested that selenium could be potentially used in the control of bacterial biofilms on the catheters [86]. Also, it was shown that selenium-containing analogs of L-proline and L-cystine are effective in the treatment of UTI [87]. A study was conducted to compare the blood level of retinol and selenium in a person who suffered from minor lower urinary lesions. The results showed that there was a significant difference in the mean blood level of selenium between cases and control groups [88].

Copper, $\mathrm{Cu}$, is an essential micronutrient for optimal innate immune function, and the nutritional deficiency of this element leads to increased susceptibility to bacterial infections [11]. During clinical UTI, uropathogenic E. coli upregulated the expression of copper efflux genes in patients. And, this element as a host effector could be involved in protection against pathogen colonization of the urinary tract [89]. Moreover, $\mathrm{Cu}$ export transport in bacteria has been addressed as an important virulence and fitness determinants during UTI [90]. Copper supplementation in drinking water has been suggested as an effective approach to reducing $E$. coli colonization in the urinary bladder of the animal model [91].

\subsubsection{Other agents}

Citrate salts could be used in the management of UTI due to their ability to alkalinize the urine, and alkaline urine is helpful for UTI symptoms such as dysuria. It was shown that by the administration of sodium citrate in women with UTI problems for $48 \mathrm{~h}$, the symptoms were significantly improved in 80 percent of the subjects [92]. Additionally, alkalinity in the urine provides an effective environment for some of the antimicrobial agents such as uva-ursi and berberine to perform their function [37]. The role of these salts in the treatment of urinary candidiasis has been mentioned in an earlier study [93].

Simple sugars such as D-mannose could prevent the adherence of pathogens to uroepithelial cells. Various evidences show that the implementation of mannose exerts beneficial results in the treatment of UTI. It was shown that a mannose-specific lectin exists on the surface of adherent strains of E. coli and the sugar acts as the primary bladder cell receptor site for UPEC to bind [94]. Likewise, it was reported that in the adhesion of UPEC to the uroepithelial cells, the first step is the binding of FimH adhesin to the bladder epithelium through the interaction of mannose moieties with the host cell surface [95]. So, the use of the sugar or its analogs can help to block the adhesion of $E$. coli to the bladder epithelium. The efficacy of these sugars in controlling UTI has been studied previously [96-98].

An in vivo study indicated that demonstrated D-mannose in mice not only blocked adhesion of $E$. coli to the epithelium of the urinary tract but also prevent bacterial invasion and biofilm formation [99]. Also, in the presence of D-mannose, the adherence of clinical isolates of $E$. coli was inhibited remarkably [100]. Oral supplementation of D-mannose decreases the perception of lower urinary tract symptoms in postmenopausal women [101]. The results of another study indicated that D-mannose efficiently blocked the adhesive properties of all type 1 fimbriae-positive isolates of $E$. coli in low concentration, but did not show any bacteriostatic effects [102]. The results of another study demonstrated that antibiotic therapy in combination with long-term enrichment of the diet with D-mannose leads to prolongation of the inter-relapse period of uncomplicated UTI [97].

The effects of different derivatives of the sugar in the control of UTIs were studied. Klein et al. synthesized and evaluated the efficacy of these sugars in blocking bacterial-host interaction. Among them, para-substituted biphenyl derivative was the most effective agent in controlling UTIs. Following oral administration of this compound, bacterial numbers were reduced by twofold and fourfold in the urine and bladder, respectively [103].

\subsection{Probiotics}

Probiotics are living microorganisms which when administered in certain numbers exert a health benefit on the host [104]. The clinical efficacy of probiotics for adjunct treatment in the treatment of different 
gastrointestinal and urinary tract infections has been addressed previously [105]. They have demonstrated positive effects in the treatment and prevention of rotavirus diarrhea and alleviation of the antibioticassociated intestinal adverse effects by recognizing the commensal microbiota and also restoration of the microbial ecosystem after an imbalance or infection [106]. Probiotics are clinically proven to be effective in the management of UTI including accelerating recovery after UTI and also decreasing recurrent UTI in children [107]. It must be emphasized that, for better effectiveness of probiotics, they must be able to colonize in the intestinal and/or urogenital region [108]. These positive effects of probiotics might be attributed to the intrinsic properties of microorganisms. For example, lactobacilli are able to grow in an environment with $\mathrm{pH} \leq 4.5$, where they could multiply and produce additional antibacterial molecules, such as bacteriocin and hydrogen peroxide [109, 110]. Besides these advantages, probiotics could produce biosurfactants that inhibit the growth of uropathogens by reducing the adhesion of the pathogens to the uroepithelium. Moreover, lactobacilli could co-aggregate with uropathogens and block their adhesion to the urinary tract and also displace previously adherent uropathogens from uroepithelium. This process can create a microenvironment in which the inhibitory products of lactobacilli can concentrate on the pathogens and therefore inhibit the pathogens [111]. It is worth noting that the most effective lactobacilli for controlling UTI are L. rhamnosus GR-1 and $L$. reuteri $\mathrm{B}-54$ and $\mathrm{RC}-14$ which have been proven [108].

The common vaginal Lactobacillus species were used to investigate the inhibition of $E$. coli growth. The results showed that when $L$. crispatus was incubated with clinical $E$. coli strains, the growth of $E$. coli was inhibited in the acidic environment [112]. Wolff et al. studied the changes in the ratio between uropathogens and Lactobacillus (U/L) within the lower UTI in response to oral probiotic supplementation. Based on the results, there were no changes between groups in terms of microbiota diversity and the use of oral probiotic did not alter the U/L ratio [113]. The physicochemical cell surface, adhesion properties, and the antagonistic activity of recombinant Lactococcus lactis containing the Ama r 2 gene against the E. coli causing UTI in humans were studied. The results indicated that this recombinant probiotic showed desirable properties and the Ama $\mathrm{r} 2$ gene expression did not affect the positive probiotic properties [114].

The ability of a clinically isolated probiotic, L. fermentum strain 4-17, to adhere to human intestinal was studied. L. fermentum strain 4-17 showed appropriate anti-adhesive properties against human pathogenic bacteria [115].
Osset et al. [116] studied the antimicrobial activities of 15 Lactobacillus species against pathogens. Among them, L. crispatus could block pathogen adhesion efficiently.

The results of another study revealed that a pyelonephritic E. coli was sensitive to L. rhamnosus, Bifidobacterium lactis, and Bifidobacterium longus and these probiotics were able to suppress the growth of enteric and urinary pathogens [117].

Oral administration of multispecies probiotic formulations showed antimicrobial activities against the pathogens that are responsible for vaginal dysbiosis and infections [118].

The effects of vaginal suppositories of probiotics for the prevention and treatment of UTI have been studied previously. The concept for instilling probiotic into the vagina might be related to the belief that by the presence of probiotic as the dominant bacterium the ascension of uropathogens into the bladder was restricted by various mechanisms, such as interfering with pathogen adhesion, biofilm formation reduction, reducing the expression of virulence factors, and also modulation of the host's defense systems to better combat infection [108]. The Lactobacillus strains inhibited the growth of $E$. coli via the production of organic acids. Additionally, the adhesion and internalization of E. coli into HeLa cells were reduced by probiotics [119]. Reid et al. investigated the effect of probiotic lactobacilli in controlling acute UTI in women. Based on the results, recurrence reduced remarkably in the Lactobacillus group compared to the placebo group [120].

Taken together, the results of these aforementioned studies demonstrated the potential benefit of probiotics in controlling UTI.

Additionally, site-oriented probiotic therapy has been recognized as one of the most promising therapeutic alternatives for the prevention of UTI in post-antibiotic therapy [112].

While most clinical research showed using these natural substances represents a promising approach, further studies are needed to prove their mechanism of action and clinical effectiveness. It should be noted that formulating these substances in a single dosage form and their side effects and interactions with each other are the main limitations of developing a new formulation.

\section{Conclusion}

Treatment with non-antibiotic agents is a good approach to reduce the risk of incidence of UTI and also decrease the symptoms of the illness. Among these agents, natural substances, nutrients, and probiotics attract attention. Each of these agents acts by a different mechanism, and therefore, co-formulation of them in a single dosage form maybe provides the natural formulation that is effective 


\section{for both preventive and therapeutic approaches in the management of UTI.}

\section{Acknowledgements \\ Not applicable.}

\section{Authors' contributions}

BK collaborated in the original idea, concept, design, and writing and drafting the article. SDF and RA contributed to data interpretation, writing, and drafting of the article. BSFB contributed to all stages of the process and mainly participated in drafting the article, writing, and editing the final version to be published. All the authors read and approved the final version of the manuscript.

\section{Funding}

The study was not funded by any authority.

\section{Availability of data and materials}

This review was based on data extracted from published papers available in all relevant databases without limitation up to October 1, 2020

\section{Ethics approval and consent to participate}

Not applicable.

\section{Consent for publication}

The study did not require consent for publication.

\section{Competing interests}

The authors declare that they have no competing interests.

\section{Author details}

1 Biotechnology Research Center, Pharmaceutical Technology Institute, Mashhad University of Medical Sciences, Mashhad, Iran. ${ }^{2}$ Department of Pharmaceutical Control, School of Pharmacy, Mashhad University of Medical Sciences, Mashhad, Iran. ${ }^{3}$ School of Pharmacy, Mashhad University of Medical Sciences, Mashhad, Iran. ${ }^{4}$ Department of Family Medicine, School of Medicine, Mashhad University of Medical Sciences, Mashhad, Iran.

Received: 21 October 2020 Accepted: 25 December 2020

Published online: 07 January 2021

\section{References}

1. Sheerin NS, Glover EK (2019) Urinary tract infection. Medicine 47:546-550

2. Sheerin NS (2011) Urinary tract infection. Medicine 39:384-389

3. Kasper DL, Fauci AS, Hauser SL, Longo DL, Jameson JL, Loscalzo J (2018) Urinary tract infections, pyelonephritis, and prostatitis. In: Harrison's principles of internal medicine, 20th edn. McGraw-Hill Education, New York

4. Freire MP, Martinho L, Mendes CV, Spadão F, De Paula FJ, Nahas WC, David-Neto E, Pierrotti LC (2020) Institutional protocol adherence in the incidence of recurrent urinary tract infection after kidney transplantation. J Glob Antimicrob Resist 23:352-358

5. Olin SJ, Bartges JW (2015) Urinary tract infections: treatment/comparative therapeutics. Vet Clin North Am Small Anim Pract 45:721-746

6. Behzadi P (2019) Classical chaperone-usher (CU) adhesive fimbriome: uropathogenic Escherichia coli (UPEC) and urinary tract infections (UTIs). Folia Microbiol (Praha)

7. Matulay JT, Mlynarczyk CM, Cooper KL (2016) Urinary tract infections in women: pathogenesis, diagnosis, and management. Curr Bladder Dysfunct Rep 11:53-60

8. Storme O, Tiran Saucedo J, Garcia-Mora A, Dehesa-Davila M, Naber KG (2019) Risk factors and predisposing conditions for urinary tract infection. Ther Adv Urol 11:1756287218814382

9. Asadi Karam MR, Habibi M, Bouzari S (2019) Urinary tract infection: pathogenicity, antibiotic resistance and development of effective vaccines against uropathogenic Escherichia coli. Mol Immunol 108:56-67
10. Lane DR, Takhar SS (2011) Diagnosis and management of urinary tract infection and pyelonephritis. Emerg Med Clin North Am 29:539-552

11. Khameneh B, Iranshahy M, Vahdati-Mashhadian N, Sahebkar A, Fazly Bazzaz BS (2019) Non-antibiotic adjunctive therapy: a promising approach to fight tuberculosis. Pharmacol Res 146:104289

12. Khameneh B, Diab R, Ghazvini K, Fazly Bazzaz BS (2016) Breakthroughs in bacterial resistance mechanisms and the potential ways to combat them. Microb Pathog 95:32-42

13. Khameneh B, Iranshahy M, Soheili V, Fazly Bazzaz BS (2019) Review on plant antimicrobials: a mechanistic viewpoint. Antimicrob Resist Infect Control 8:118

14. Bazzaz BSF, Fakori M, Khameneh B, Hosseinzadeh H (2019) Effects of omeprazole and caffeine alone and in combination with gentamicin and ciprofloxacin against antibiotic resistant staphylococcus aureus and Escherichia coli strains. J Pharmacopuncture 22:49-54

15. Fazly Bazzaz BS, Khameneh B, Zahedian Ostad MR, Hosseinzadeh H (2018) In vitro evaluation of antibacterial activity of verbascoside, lemon verbena extract and caffeine in combination with gentamicin against drug-resistant Staphylococcus aureus and Escherichia coli clinical isolates. Avicenna J Phytomed 8:246-253

16. Fazly Bazzaz BS, Sarabandi S, Khameneh B, Hosseinzadeh H (2016) Effect of catechins, green tea extract and methylxanthines in combination with gentamicin against Staphylococcus aureus and Pseudomonas aeruginosa: combination therapy against resistant bacteria. J Pharmacopuncture 19:312-318

17. Baker JH, Qiu J, Grine K (2018) Role of complementary and alternative therapies in infectious disease. Prim Care Clin Off Pract 45:533-539

18. Mantzorou M, Giaginis C (2018) Cranberry consumption against urinary tract infections: clinical state-of-the-art and future perspectives. Curr Pharm Biotechnol 19:1049-1063

19. Poulios E, Vasios GK, Psara E, Giaginis C (2020) Medicinal plants consumption against urinary tract infections: a narrative review of the current evidence. Expert Rev Anti Infect Ther 2020:1-10

20. Loubet $P$, Ranfaing J, Dinh A, Dunyach-Remy $C$, Bernard L, Bruyère $F$, Lavigne J-P, Sotto A (2020) Alternative therapeutic options to antibiotics for the treatment of urinary tract infections. Front Microbiol 11:1

21. Farhadi F, Khameneh B, Iranshahi M, Iranshahy M (2019) Antibacterial activity of flavonoids and their structure-activity relationship: an update review. Phytother Res 33:13-40

22. Shaheen G, Akram M, Jabeen F, Ali Shah SM, Munir N, Daniyal M, Riaz M, Tahir IM, Ghauri AO, Sultana S, Zainab R, Khan M (2019) Therapeutic potential of medicinal plants for the management of urinary tract infection: a systematic review. Clin Exp Pharmacol Physiol 46:613-624

23. Yarnell E (2002) Botanical medicines for the urinary tract. World J Urol 20:285-293

24. Bag A, Bhattacharyya S, Chattopadhyay R (2008) Medicinal plants and urinary tract infections: an update. Phcog Rev 2:277

25. Marino A, Bellinghieri V, Nostro A, Miceli N, Taviano MF, Guvenc A, Bisignano $G$ (2010) In vitro effect of branch extracts of Juniperus species from Turkey on Staphylococcus aureus biofilm. FEMS Immunol Med Microbiol 59:470-476

26. Schilcher $\mathrm{H}$ (1995) Juniper berry oil in diseases of the efferent urinary tract? Med Monatsschr Pharm 18:198-199

27. Pepeljnjak S, Kosalec I, Kalodera Z, Blazevic N (2005) Antimicrobial activity of juniper berry essential oil (Juniperus communis L., Cupressaceae). Acta Pharm 55:417-422

28. Howell AB, Foxman B (2002) Cranberry juice and adhesion of antibioticresistant uropathogens. JAMA 287:3082-3083

29. Burger O, Ofek I, Tabak M, Weiss El, Sharon N, Neeman I (2000) A high molecular mass constituent of cranberry juice inhibits Helicobacter pylori adhesion to human gastric mucus. FEMS Immunol Med Microbiol 29:295-301

30. Di Martino P, Agniel R, David K, Templer C, Gaillard JL, Denys P, Botto H (2006) Reduction of Escherichia coli adherence to uroepithelial bladder cells after consumption of cranberry juice: a double-blind randomized placebo-controlled cross-over trial. World J Urol 24:21-27

31. Tao Y, Pinzon-Arango PA, Howell AB, Camesano TA (2011) Oral consumption of cranberry juice cocktail inhibits molecular-scale adhesion of clinical uropathogenic Escherichia coli. J Med Food 14:739-745 
32. LaPlante KL, Sarkisian SA, Woodmansee S, Rowley DC, Seeram NP (2012) Effects of cranberry extracts on growth and biofilm production of Escherichia coli and Staphylococcus species. Phytother Res 26:1371-1374

33. Howell AB, Reed JD, Krueger CG, Winterbottom R, Cunningham DG, Leahy M (2005) A-type cranberry proanthocyanidins and uropathogenic bacterial anti-adhesion activity. Phytochemistry 66:2281-2291

34. Raditic DM (2015) Complementary and integrative therapies for lower urinary tract diseases. Vet Clin North Am Small Anim Pract 45:857-878

35. Dason S, Dason JT, Kapoor A (2011) Guidelines for the diagnosis and management of recurrent urinary tract infection in women. Can Urol Assoc J 5:316-322

36. Davidson E, Zimmermann BF, Jungfer E, Chrubasik-Hausmann S (2014) Prevention of urinary tract infections with Vaccinium products. Phytother Res 28:465-470

37. Head KA (2008) Natural approaches to prevention and treatment of infections of the lower urinary tract. Altern Med Rev 13:227-244

38. Mary Anne Roshni Amalaradjou, Venkitanarayanan K (2011) Natural approaches for controlling urinary tract infections. In: Tenke P (ed) Urinary tract infections. InTech, New York, pp 227-244

39. Geetha RV, Roy A, Lakshmi T (2011) Nature's weapon against urinary tract infections. Int J Drug Dev Res 3:85-100

40. Geetha RV, Roy A, Lakshmi T (2012) In vitro evaluation of anti bacterial activity of leaf extract of Agathosma betulina on urinary tract pathogens. Intl J Pharm Sci Rev Res 14:94-97

41. Rafsanjany N, Lechtenberg M, Petereit F, Hensel A (2013) Antiadhesion as a functional concept for protection against uropathogenic Escherichia coli: In vitro studies with traditionally used plants with antiadhesive activity against uropathogenic Escherichia coli. J Ethnopharmacol 145:591-597

42. Williams G, Craig JC (2009) Prevention of recurrent urinary tract infection in children. Curr Opin Infect Dis 22:72-76

43. Mutters NT, Mampel A, Kropidlowski R, Biehler K, Günther F, Bălu I, Malek V, Frank U (2018) Treating urinary tract infections due to MDR E. coli with Isothiocyanates - a phytotherapeutic alternative to antibiotics? Fitoterapia 129:237-240

44. Drew A (2000) Goldenseal. Curr Ther 41:47-48

45. Tims M, Batista C (2007) Effects of root isoquinoline alkaloids from Hydrastis canadensis on Fusarium oxysporum isolated from Hydrastis root tissue. J Chem Ecol 33:1449-1455

46. Genovese C, Davinelli S, Mangano K, Tempera G, Nicolosi D, Corsello S, Vergalito F, Tartaglia E, Scapagnini G, Di Marco R (2018) Effects of a new combination of plant extracts plus $d$-mannose for the management of uncomplicated recurrent urinary tract infections. J Chemother 30:107-114

47. Ceyhan N, Keskin D, Uğur A (2012) Antimicrobial activities of different extracts of eight plant species from four different family against some pathogenic microorganisms. J Food Agric Environ 10:193-197

48. Das G, Patra JK, Baek KH (2017) Antibacterial properties of endophytic bacteria isolated from a fern species Equisetum arvense L. against foodborne pathogenic bacteria Staphylococcus aureus and Escherichia coli 0157:H7. Foodborne Pathog Dis 14:50-58

49. Asgarpanah J, Roohi E (2012) Phytochemistry and pharmacological properties of Equisetum arvense L. J Med Plants Res 6:3689-3693

50. Radojevic ID, Stankovic MS, Stefanovic OD, Topuzovic MD, Comic LR, Ostojic AM (2012) Great horsetail (Equisetum telmateia Ehrh.): active substances content and biological effects. EXCLI J 11:59-67

51. Chrubasik JE, Roufogalis BD, Wagner H, Chrubasik SA (2007) A comprehensive review on nettle effect and efficacy profiles, part I: Herba urticae. Phytomedicine 14:423-435

52. Kukrić ZZ, Topalić-Trivunović LN, Kukavica BM, Matoš SB, Pavičić SS, Boroja MM, Savić AV (2012) Characterization of antioxidant and antimicrobial activities of nettle leaves (Urtica dioica L.). Acta Periodica Technol 2012:257-272.

53. Balkhi TMB, Bhat FA (2012) Bioactive potential of leaf extracts from Urtica dioica L. against fish and human pathogenic bacteria. Afr J Microbiol Res 6:6893-6899

54. Kreft S, Lunder M (2011) Herbal medicinal products for the treatment of the urogenital infection. Farm Vestn 62:87-95
55. Bahmani M, Saki K, Shahsavari S, Rafieian-Kopaei M, Sepahvand R, Adineh A (2015) Identification of medicinal plants effective in infectious diseases in Urmia, northwest of Iran. Asian Pac J Trop Biomed 5:858-864

56. Shaaban MT, Ghozlan HA, El Maghraby MM (2012) Susceptibility of bacteria infecting urinary tract to some antibiotics and essential oils. JAPS 2:9

57. Kwiecińska-Piróg J, Skowron K, Bogiel T, Białucha A, Przekwas J, Gospodarek-Komkowska E (2019) Vitamin C in the presence of sub-Inhibitory concentration of aminoglycosides and fluoroquinolones alters Proteus mirabilis biofilm inhibitory rate. Antibiotics 8:116

58. Monroy-Torres R, Medina-Jiménez AK (2019) Cranberry juice and other functional foods in urinary tract infections in women: a review of actual evidence and main challenges. Front Clin Drug Res Anti Infect. https:// doi.org/10.2174/9781681086378119050007

59. Yousefichaijan P, Goudarzi AA, Rezagholizamenjany M, Kahbazi M, Rafeie M, Shabestari AA, Shariatmadari F, Taherahmadi H (2018) Efficacy of ascorbic acid supplementation in relief of symptoms due to febrile upper urinary tract infection in children, a clinical trial and hospital based study. Arch Pediatric Infect Dis 6:e57071

60. Ochoa-Brust GJ, Fernandez AR, Villanueva-Ruiz GJ, Velasco R, TrujilloHernandez B, Vasquez C (2007) Daily intake of 100 mg ascorbic acid as urinary tract infection prophylactic agent during pregnancy. Acta Obstet Gynecol Scand 86:783-787

61. Manzoor MAP, Duwal SR, Mujeeburahiman M, Rekha PD (2018) Vitamin C inhibits crystallization of struvite from artificial urine in the presence of Pseudomonas aeruginosa. Int Braz J Urol 44:1234-1242

62. Montorsi F, Gandaglia G, Salonia A, Briganti A, Mirone V (2016) Effectiveness of a combination of cranberries, Lactobacillus rhamnosus, and vitamin $\mathrm{C}$ for the management of recurrent urinary tract infections in women: results of a pilot study. Eur Urol 70:912-915

63. Carlsson S, Wiklund NP, Engstrand L, Weitzberg E, Lundberg JON (2001) Effects of $\mathrm{pH}$, nitrite, and ascorbic acid on nonenzymatic nitric oxide generation and bacterial growth in urine. Nitric Oxide Biol Chem 5:580-586

64. Yoo C, Kim CS (2008) Complementary and alternative medicine in urology. Korean J Urol 49:193-202

65. Yilmaz A, Bahat E, Yilmaz GG, Hasanoglu A, Akman S, Guven AG (2007) Adjuvant effect of vitamin $A$ on recurrent lower urinary tract infections. Pediatr Int 49:310-313

66. Kahbazi M, Sharafkhah M, Yousefichaijan P, Taherahmadi H, Rafiei M, Kaviani P, Abaszadeh S, Massoudifar A, Mohammadbeigi A (2019) Vitamin A supplementation is effective for improving the clinical symptoms of urinary tract infections and reducing renal scarring in girls with acute pyelonephritis: a randomized, double-blind placebo-controlled, clinical trial study. Complement Ther Med 42:429-437

67. Sobouti B, Hooman N, Movahed M (2013) The effect of vitamin e or vitamin $A$ on the prevention of renal scarring in children with acute pyelonephritis. Pediatr Nephrol 28:277-283

68. Ayazi P, Moshiri SA, Mahyar A, Moradi M (2011) The effect of vitamin A on renal damage following acute pyelonephritis in children. Eur J Pediatr 170:347-350

69. Smith JM, Cancienne JM, Brockmeier SF, Werner BC (2020) Vitamin D deficiency and total shoulder arthroplasty complications. Shoulder Elbow

70. Hertting $O$, Lüthje P, Sullivan D, Aspenström P, Brauner A (2017) Vitamin D-deficient mice have more invasive urinary tract infection. PLoS ONE 12:e0180810

71. Ramos NL, Sekikubo M, Kironde F, Mirembe F, Sääf M, Brauner A (2015) The impact of vitamin D on the innate immune response to uropathogenic Escherichia coli during pregnancy. Clin Microbiol Infect 21:482. e481-482.e487

72. Deng QF, Chu H, Wen Z, Cao YS (2019) Vitamin D and urinary tract infection: a systematic review and meta-analysis. Ann Clin Lab Sci 49:134-142

73. Handoka NM, Amin RE, Shalaby SA (2018) Vitamin D deficiency is associated with urinary tract infection in children. Arch Med Sci 14:115-121

74. Tekin M, Konca C, Celik V, Almis H, Kahramaner Z, Erdemir A, Gulyuz A, Uckardes F, Turgut M (2015) The association between Vitamin D levels and urinary tract infection in children. Horm Res Paediatr 83:198-203 
75. Haghdoost S, Pazandeh F, Darvish S, Khabazkhoob M, Huss R, Lak TB (2019) Association of serum vitamin D levels and urinary tract infection in pregnant women: a case control study. Eur J Obstet Gynecol Reprod Biol 243:51-56

76. Georgieva V, Kamolvit W, Herthelius M, Lüthje P, Brauner A, Chromek M (2019) Association between vitamin D, antimicrobial peptides and urinary tract infection in infants and young children. Acta Paediatr Int J Paediatr 108:551-556

77. Jorde R, Sollid ST, Svartberg J, Joakimsen RM, Grimnes G, Hutchinson MYS (2016) Prevention of urinary tract infections with vitamin D supplementation 20,000 IU per week for five years. Results from an RCT including 511 subjects. Infect Dis 48:823-828

78. Hemila H, Chalker $\mathrm{E}$ (2015) The effectiveness of high dose zinc acetate lozenges on various common cold symptoms: a meta-analysis. BMC Fam Pract 16:24

79. Consolo LZZ, Melnikov P, Cônsolo FZ, Nascimento VA, Pontes JCDV (2013) Zinc supplementation in children and adolescents with acute leukemia. Eur J Clin Nutr 67:1056-1059

80. Haider BA, Lassi ZS, Ahmed A, Bhutta ZA (2011) Zinc supplementation as an adjunct to antibiotics in the treatment of pneumonia in children 2 to 59 months of age. Cochrane Datab Syst Rev 1:1

81. Chohan ZH, Arif M, Shafiq Z, Yaqub M, Supuran CT (2006) In vitro antibacterial, antifungal and cytotoxic activity of some isonicotinoylhydrazide Schiff's bases and their cobalt(II), copper(II), nickel(II) and zinc(II) complexes. J Enzyme Inhib Med Chem 21:95-103

82. Dizdar OS, Baspınar O, Kocer D, Dursun ZB, Avcı D, Karakükcü C, Çelik I, Gundogan K (2016) Nutritional risk, micronutrient status and clinical outcomes: a prospective observational study in an infectious disease clinic. Nutrients 8:1

83. Hamer DH, Sempértegui F, Estrella B, Tucker KL, Rodríguez A, Egas J, Dallal GE, Selhub J, Griffiths JK, Meydani SN (2009) Micronutrient deficiencies are associated with impaired immune response and higher burden of respiratory infections in elderly Ecuadorians. J Nutr 139:113-119

84. Mohsenpour B, Ahmadi A, Baneh AM, Hajibagheri K, Ghaderi E, Afrasiabian S, Azizi S (2019) Relation between serum zinc levels and recurrent urinary tract infections in female patients: a case-control study. Med J Islam Repub Iran 33:199-201

85. Nia SJ, Noorbakhsh S, Izadi A, Pour FS, Tabatabaei A, Shokrollahi MR (2013) Comparison of vitamin A, D \& zinc serum levels between children with urinary tract infection and control group in two University Hospital. Tehran Uni Med J 71:244-249

86. Narayanan A, Nair MS, Muyyarikkandy MS, Amalaradjou MA (2018) Inhibition and inactivation of uropathogenic Escherichia coli Biofilms on urinary catheters by Sodium Selenite. Int J Mol Sci 19:1

87. Deutch CE, Spahija I, Wagner CE (2014) Susceptibility of Escherichia coli to the toxic L-proline analogue L-selenaproline is dependent on two L-cystine transport systems. J Appl Microbiol 117:1487-1499

88. Hafez AS, Fahim HI, Wafaay H, Mohamed FA (1993) A comparative study of blood retinol and selenium in minor lower urinary lesions. A case control study. J Egypt Public Health Assoc 68:247-263

89. Hyre AN, Kavanagh K, Kock ND, Donati GL, Subashchandrabose S (2017) Copper is a host effector mobilized to urine during urinary tract infection to impair bacterial colonization. Infect Immun 85:1

90. Subashchandrabose S, Mobley HLT (2015) Back to the metal age: battle for metals at the host-pathogen interface during urinary tract infection. Metallomics 7:935-942

91. Subashchandrabose S, Hazen TH, Brumbaugh AR, HimpsI SD, Smith SN, Ernst RD, Rasko DA, Mobley HLT (2014) Host-specific induction of Escherichia coli fitness genes during human urinary tract infection. Proc Natl Acad Sci USA 111:18327-18332

92. Spooner JB (1984) Alkalinisation in the management of cystitis. J Int Med Res 12:30-34

93. Strassner C, Friesen A (1995) Therapy of candiduria by alkalinization of urine. Oral treatment with potassium-sodium-hydrogen citrate. Fortschr Med 113:359-362

94. Firon N, Ashkenazi S, Mirelman D, Ofek I, Sharon N (1987) Aromatic alpha-glycosides of mannose are powerful inhibitors of the adherence of type 1 fimbriated Escherichia coli to yeast and intestinal epithelial cells. Infect Immun 55:472-476

95. Schaeffer AJ (2003) Structural basis of tropism of Escherichia coli to the bladder during urinary tract infection. J Urol 170:335
96. Scribano D, Sarshar M, Prezioso C, Lucarelli M, Angeloni A, Zagaglia C, Palamara AT, Ambrosi C (2020) D-Mannose treatment neither affects uropathogenic Escherichia coli properties nor induces stable fimh modifications. Molecules 25:1

97. Kuzmenko AV, Kuzmenko W, Gyaurgiev TA (2019) Efficacy of combined antibacterial-prebiotic therapy in combination with d-mannose in women with uncomplicated lower urinary tract infection. Urologiia 2019:38-43

98. Duncan D (2019) Alternative to antibiotics for managing asymptomatic and non-symptomatic bacteriuria in older persons: a review. Brit J Community Nurs 24:116-119

99. Wellens A, Garofalo C, Nguyen H, Van Gerven N, Slattegard R, Hernalsteens JP, Wyns L, Oscarson S, De Greve H, Hultgren S, Bouckaert J (2008) Intervening with urinary tract infections using anti-adhesives based on the crystal structure of the FimH-oligomannose-3 complex. PLoS ONE 3:e2040

100. Schaeffer AJ, Chmiel JS, Duncan JL, Falkowski WS (1984) Mannosesensitive adherence of Escherichia coli to epithelial cells from women with recurrent urinary tract infections. J Urol 131:906-910

101. Russo E, Montt Guevara M, Giannini A, Mannella P, Palla G, Caretto M, Pancetti F, Genazzani AD, Simoncini T (2020) Cranberry, D-mannose and anti-inflammatory agents prevent lower urinary tract symptoms in women undergoing prolapse surgery. Climacteric 23:201-205

102. Marcon J, Schubert S, Stief CG, Magistro G (2019) In vitro efficacy of phytotherapeutics suggested for prevention and therapy of urinary tract infections. Infection 47:937-944

103. Klein T, Abgottspon D, Wittwer M, Rabbani S, Herold J, Jiang X, Kleeb S, Luthi C, Scharenberg M, Bezencon J, Gubler E, Pang L, Smiesko M, Cutting B, Schwardt O, Ernst B (2010) FimH antagonists for the oral treatment of urinary tract infections: from design and synthesis to in vitro and in vivo evaluation. J Med Chem 53:8627-8641

104. Gorbach SL (2002) Probiotics in the third millennium. Dig Liver Dis 34(Suppl 2):S2-7

105. Amdekar S, Singh V, Singh DD (2011) Probiotic therapy: immunomodulating approach toward urinary tract infection. Curr Microbiol 63:484-490

106. Marteau P, Boutron-Ruault MC (2002) Nutritional advantages of probiotics and prebiotics. Br J Nutr 87(Suppl 2):S153-157

107. Prasetyo RV, Surono I, Soemyarso NA, Djojodimedjo T, Rauf S, Noer MS, Sudarmo SM (2020) Lactobacillus plantarum IS-10506 promotes renal tubular regeneration in pyelonephritic rats. Benef Microbes 11:59-66

108. Reid G, Bruce AW (2006) Probiotics to prevent urinary tract infections: the rationale and evidence. World J Urol 24:28-32

109. Petraitytè S, Šipailienè A (2019) Enhancing encapsulation efficiency of alginate capsules containing lactic acid bacteria by using different divalent cross-linkers sources. LWT 110:307-315

110. Aroutcheva A, Gariti D, Simon M, Shott S, Faro J, Simoes JA, Gurguis A, Faro S (2001) Defense factors of vaginal lactobacilli. Am J Obstet Gynecol 185:375-379

111. Mastromarino P, Brigidi P, Macchia S, Maggi L, Pirovano F, Trinchieri V, Conte U, Matteuzzi D (2002) Characterization and selection of vaginal Lactobacillus strains for the preparation of vaginal tablets. J Appl Microbiol 93:884-893

112. Hudson PL, Hung KJ, Bergerat A, Mitchell C (2020) Effect of vaginal Lactobacillus species on Escherichia coli growth. Female Pelvic Med Reconstr Surg 26:146-151

113. Wolff BJ, Price TK, Joyce CJ, Wolfe AJ, Mueller ER (2019) Oral probiotics and the female urinary microbiome: a double-blinded randomized placebo-controlled trial. Int Urol Nephrol 51:2149-2159

114. Vasiee A, Mortazavi SA, Sankian M, Yazdi FT, Mahmoudi M, Shahidi F (2019) Antagonistic activity of recombinant Lactococcus lactis NZ1330 on the adhesion properties of Escherichia coli causing urinary tract infection. Microb Pathog 133:103547

115. Falah F, Vasiee A, Behbahani BA, Yazdi FT, Moradi S, Mortazavi SA, Roshanak S (2019) Evaluation of adherence and anti-infective properties of probiotic Lactobacillus fermentum strain 4-17 against Escherichia coli causing urinary tract infection in humans. Microb Pathog $131: 246-253$

116. Osset J, Bartolome RM, Garcia E, Andreu A (2001) Assessment of the capacity of Lactobacillus to inhibit the growth of uropathogens and block their adhesion to vaginal epithelial cells. J Infect Dis 183:485-491 
117. Hutt P, Shchepetova J, Loivukene K, Kullisaar T, Mikelsaar M (2006) Antagonistic activity of probiotic lactobacilli and bifidobacteria against entero- and uropathogens. J Appl Microbiol 100:1324-1332

118. Mezzasalma V, Manfrini E, Ferri E, Boccarusso M, Di Gennaro P, Schiano I, Michelotti A, Labra M (2017) Orally administered multispecies probiotic formulations to prevent uro-genital infections: a randomized placebocontrolled pilot study. Arch Gynecol Obstet 295:163-172

119. Leccese Terraf MC, Juarez Tomás MS, Rault L, Le Loir Y, Even S, NaderMacías MEF (2017) In vitro effect of vaginal lactobacilli on the growth and adhesion abilities of uropathogenic Escherichia coli. Arch Microbiol 199:767-774
120. Reid G, Bruce AW, Taylor M (1992) Influence of three-day antimicrobial therapy and Lactobacillus vaginal suppositories on recurrence of urinary tract infections. Clin Ther 14:11-16

\section{Publisher's Note}

Springer Nature remains neutral with regard to jurisdictional claims in published maps and institutional affiliations.

\section{Submit your manuscript to a SpringerOpen ${ }^{\circ}$ journal and benefit from:}

- Convenient online submission

- Rigorous peer review

- Open access: articles freely available online

- High visibility within the field

- Retaining the copyright to your article

Submit your next manuscript at $\boldsymbol{\nabla}$ springeropen.com 